\title{
Women in hospital medicine in the United Kingdom: glass ceiling, preference, prejudice or cohort effect?
}

\author{
I C McManus, K A Sproston
}

\begin{abstract}
Objective-To assess from official statistics whether there is evidence that the careers of women doctors in hospitals do not progress in the same way as those of men.

Design-The proportions of female hospital doctors overall (1963-96), and in the specialties of medicine, surgery, obstetrics and gynaecology, pathology, radiology/ radiotherapy, anaesthetics and psychiatry (1974-1996) were examined. Additionally data were examined on career preferences and intentions from pre-registration house officers, final year medical students, and medical school applicants (1966-1991).
\end{abstract}

Analysis-Data were analysed according to cohort of entry to medical school to assess the extent of disproportionate promotion.

Results-The proportion of women in hospital career posts was largely explained by the rapidly increasing proportion of women entering medical school during the past three decades. In general there was little evidence for disproportionate promotion of women in hospital careers, although in surgery, hospital medicine and obstetrics and gynaecology, fewer women seemed to progress beyond the SHO grade, and in anaesthetics there were deficits of women at each career stage. Analyses of career preferences and intentions suggest that disproportionate promotion cannot readily be explained as differential choice by women.

Conclusions-Although there is no evidence as such of a "glass ceiling" for women doctors in hospital careers, and the current paucity of women consultants primarily reflects historical trends in the numbers of women entering medical school, there is evidence in some cases of disproportionate promotion that is best interpreted as direct or indirect discrimination.

(F Epidemiol Community Health 2000;54:10-16)

In 1987 Frances Lefford, ${ }^{1}$ in an influential paper examining the proportions of women in hospital careers in England and Wales, concluded that "the number of women consultants remains disproportionately low ... even allowing for the inevitable time lag [of women medical students progressing to consultant posts]", and she contrasted specialties such as psychia- try, pathology and radiotherapy/radiology ("Cinderella specialties" ${ }^{2}$ ), where women consultants had increased in number, with "the three most popular and competitive disciplines - surgery, medicine and obstetrics and gynaecology (O and $\mathrm{G})$ - (where) the proportion (had) not changed substantially". She concluded, "The record suggests that being female is a handicap to achieving consultant status, particularly in the popular specialities". Lefford's view is echoed in other $\mathrm{UK}^{3-5}$ and $\mathrm{US}^{6}$ studies, including Isobel Allen's influential Doctors and their careers, ${ }^{78}$ which stimulated the Department of Health's Women in Surgery Training (WIST) ${ }^{9}$ scheme.

Interpreting data on the proportions of women in hospital careers is not straightforward as groups such as consultants, senior registrars, etc, are a mixture of medical school entry cohorts. A typical consultant ${ }^{10}$ might enter medical school at 18 , qualify at 23 , become a senior house officer (SHO) at 25, a registrar at 28, a senior registrar $(\mathrm{SR})$ at 31 and a consultant at 36, retiring at about age 62. An average $\mathrm{SHO}$, registrar, senior registrar or consultant is therefore about $26,29,33$ or 49; and hence a typical SHO, registrar, SR or consultant in 1993 entered medical school in $1985,1982,1978$ or 1962 , with the consultants aged between 36 and 62 entering medical school from 1949 to 1975 . The proportion of women medical students remained between 20 and $25 \%$ until 1968, since when it increased steadily, exceeding $50 \%$ in 1991 . Most consultants in 1993 had therefore entered medical school before the recent rise in female entrants, and hence cohort effects may explain Lefford's apparent shortfall of women consultants relative to women medical students (see fig 1). The apparent shortfall of women consultants may also result from what we will call here discrimination, women being promoted less than men, ${ }^{11}$ the so called "glass ceiling" 12 beyond which women do not rise. Discrimination may be direct discrimination, as with promotion committees not appointing women, or outright disparagement of their abilities and a refusal to promote,${ }^{13}$ or indirect discrimination resulting from women being "persuaded" not to apply for promotion, by inappropriate working conditions, by less access to informal patronage networks, ${ }^{7}$ by the "Salieri effect" 15 of faint praise and subtle denigration, or by mistreatment and harassment. ${ }^{16-18}$ Differential choice may also occur if women choose not to enter some specialties, although the distinction from 


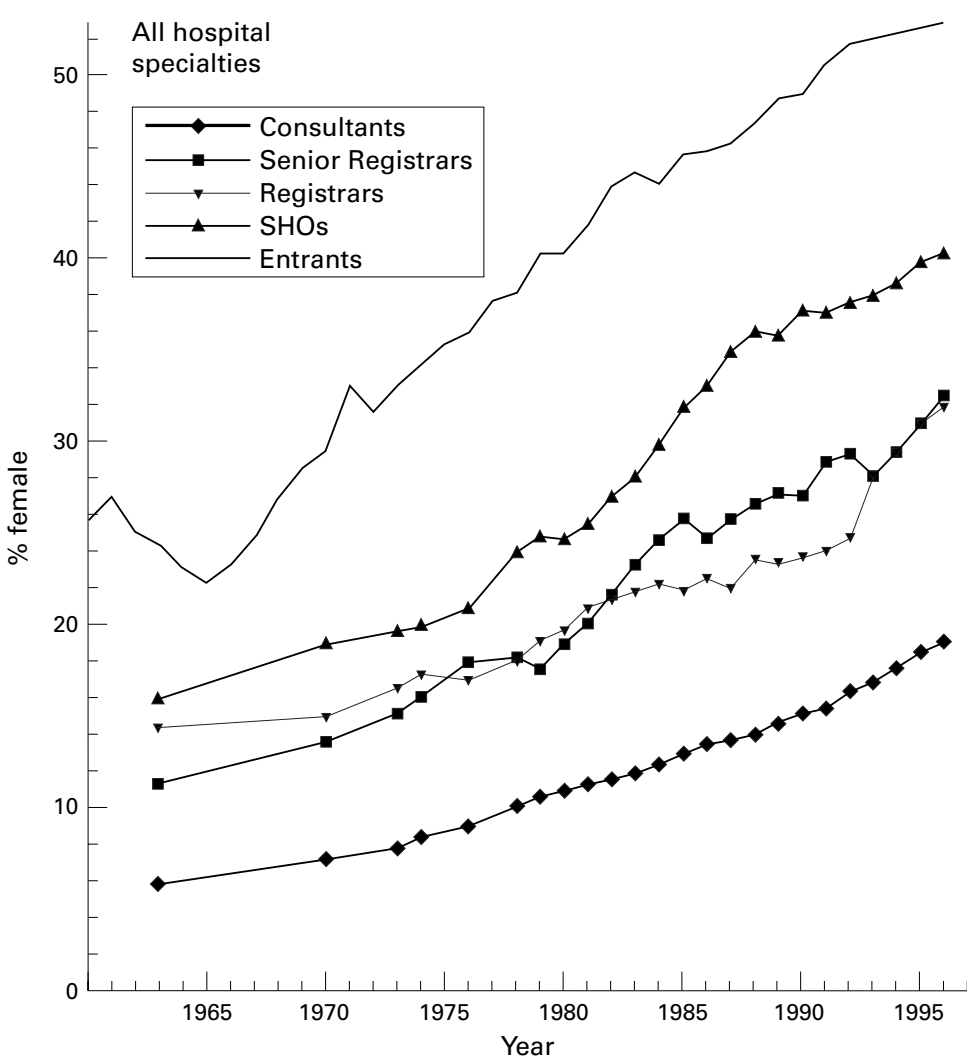

Figure 1 Proportion of female medical school entrants and female doctors at various stages of hospital careers for the years 1963 to 1996. Medical student data are obtained from official UCCA and UCAS statistics for "home" students, and from the Todd Report" ;ata on hospital doctors are for all people in the career grade in NHS hospitals in England and Wales, as published for the years 1978 to 1993 in Health Trends, for 1994 to 1996 in unpublished NHS data, and for earlier dates as published elsewhere. ${ }^{3840}$

discrimination is inevitably blurred as apparent "choice" may actually result from discouragement or lack of role models. Discrimination and differential choice cause disproportionate promotion with fewer women at higher career grades; its absence usually means the absence of both discrimination and differential choice. Interpretation of statistical data must also consider secular trends, specialties changing their attraction at different time periods.

The concept of a "glass ceiling" is a recurrent one in the recent literature on the career problems of women. It has been defined in Merriam-Webster's Collegiate Dictionary (10th edition) as: "glass ceiling $\mathrm{n}$ (1986): an intangible barrier within the hierarchy of a company that prevents women or minorities from obtaining upper-level positions."

The phrase has been used in the titles of several recent scholarly papers on the promotion of women within the US health care system, ${ }^{19-21}$ albeit with discrepant conclusions, that "objective evidence shows that women can succeed and are succeeding in gaining promotions in academic medicine", 19 or that "women physician medical school faculty are promoted more slowly than men". ${ }^{20}$

In this study we use official NHS statistics, coupled with data on career preference in medical students and recent graduates, to assess disproportionate promotion overall and in the main hospital specialties.

\section{Method}

The data for this study were obtained from several different sources. Women in hospital career posts. Since 1978 the Department of Health has published statistics on the proportion of women in hospital specialties at each career grade. ${ }^{2-37}$ Occasional other statistics have been published for some earlier dates. ${ }^{38-40}$ Data for 1993 to 1996 were also made available to the author by the Department of Health in the form of Excel spreadsheets. ${ }^{\star}$ It should be remembered in interpreting these data that they apply to all doctors employed in the NHS, whether graduating in the UK or not. Women entering medical school. UCCA (Universities' Central Council on Admissions; now UCAS (Universities and Colleges Admissions Service) has published since 1967 the proportion of women admitted to UK medical schools; before 1967 the proportion of women entrants has been estimated from data in various Royal Commissions and official reports. ${ }^{41-45}$ Career preferences of recent medical graduates. Parkhouse and colleagues have published data on medical graduates' first choice of career preference from 1974 to $1983,{ }^{5}$ as also did Last and Stanley ${ }^{46}$ for 1966 , and recently data have also been published for $1993 .^{47}$ Career preferences of medical students. Our cohort studies of student selection collected similar data to those of Parkhouse et al for applicants in the $1981,{ }^{48}$ $1986^{49}$ and $1991^{50}$ cohorts, and for final year students in the 1981 and 1986 entry cohorts. ${ }^{51}$ The typical ages at which medical students and doctors pass through the various career stages have been described above.

\section{STATISTICAL ANALYSIS}

Cohort analysis was by graphical replotting of data in terms of estimated entry cohorts (see Results section).

\section{Results}

HOSPITAL CAREERS IN GENERAL

Figure 1, plotted as have Lefford ${ }^{1}$ and others, ${ }^{9}$ suggests that the proportion of women in senior career grades has perhaps accelerated less than women entering medical school, although interpretation is difficult as different grades come from different entry cohorts. Figure 2 replots the data ${ }^{2}$ in a cohort analysis with the abscissa showing average medical school entry year for a typical person at that grade, for example, the 1993 figures are plotted at 1962 for consultants, 1978 for SRs, 1982 for Registrars and 1985 for SHOs. The graph now shows a mostly seamless progression from

* In the UK the career structure of doctors changed in the early 1990 s. Before that hospital doctors had proceeded through the hierarchy of house officer (pre-registration and not considered here), senior house officer (SHO), registrar, senior registrar, and consultant. As a result of the Calman Report in 1993, the registrar/senior registrar grade was replaced between December 1995 and January 1997 by a composite grade of specialist registrar (SpR). The data for 1993-1995 are under the old system but provide information only on SHO, "registrar grade", and but provide information only on SHO, "registrar grades", and consultant, and the data for 1996 give SHO, registrar, SpR, and consultant (registrar presumably referring to those in nonCalmanised registrar posts). For the present analysis the "registrar have been used for registrars and the SpR data for senior registrars. 


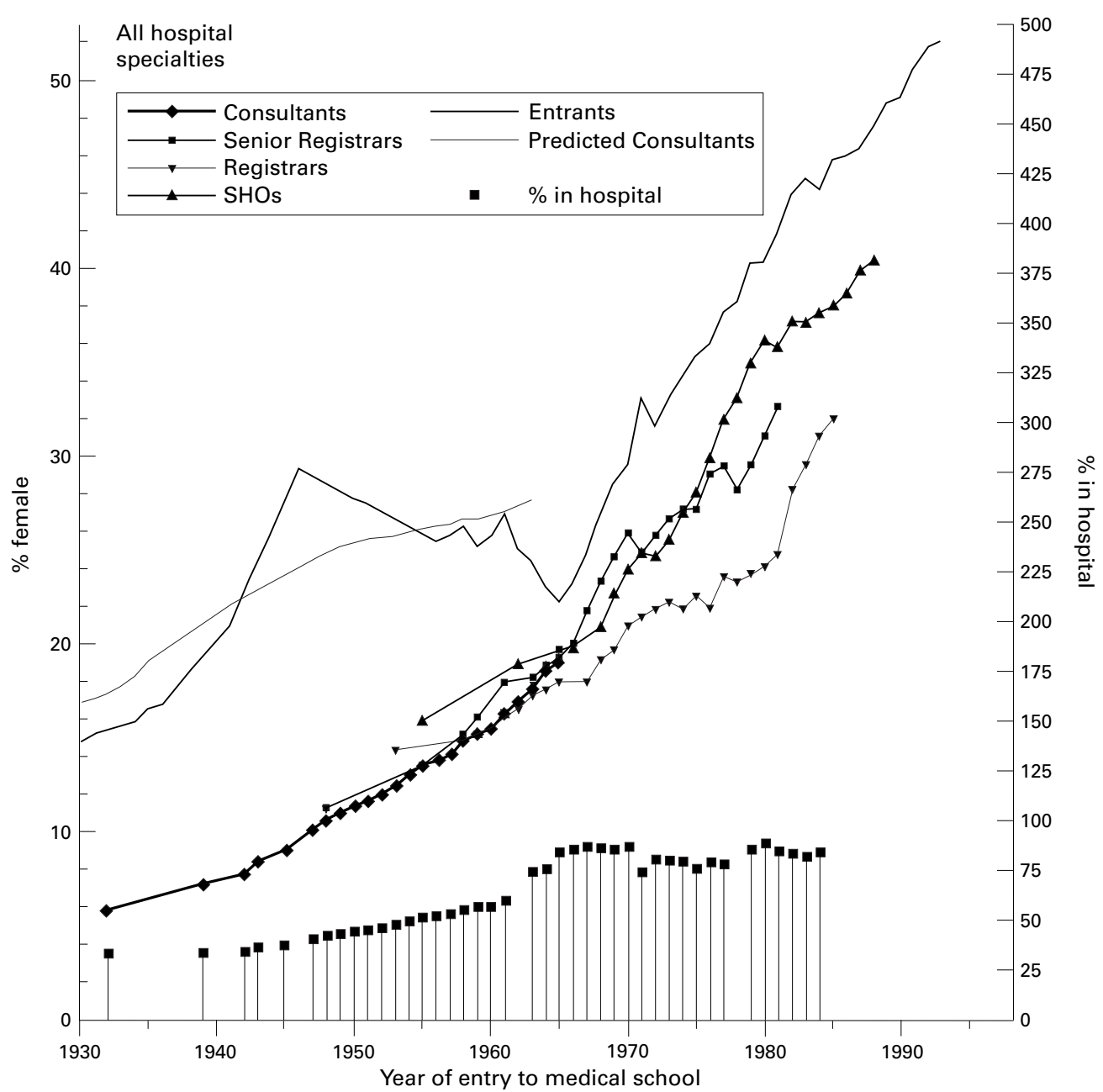

Figure 2 The thicker solid line shows the proportion of women entering UK medical schools for the years 1930-1996. Figures for 1967-1996 are derived from UCCA statistics for home students, figures for 1956-1966 are derived from Appendix 9 of the Royal Commission on Medical Education, ${ }^{45}$ and data before 1946 have been estimated from data presented in the Willink report, ${ }^{44}$ and the Goodenough Report ${ }^{41}$ with linear interpolation. The thinner solid line shows the expected proportion of women among doctors aged 36-62 (that is, consultant age) as a function of the "typical" age of the consultant. Expected proportions for doctors of the age range of SRs, Registrars and SHOs are almost exactly as shown by the proportion of women medical school entrants and are not shown separately. Solid lines show the same data as those of figure 1 for the proportion of women in hospital career grades but plotted in relation to the typical median year of entry for that cohort of graduates (see text for further details). The bars at the bottom of the figure (\% in hospital on the right hand axis) show the proportion of women in hospital careers as a percentage of the proportion of women entering medical school; a figure of $100 \%$ indicates that a female medical school entrant is as likely to be in a hospital post as is a male medical school entrant. Figures up to 1961 are for consultants, from 1963 to 1977 for SRs, and for subsequent dates for SHOs.

SHO grade to SR and consultant, with no disproportionate promotion and hence neither discrimination nor differential choice. Although the proportion of women hospital doctors does remain less than the proportion entering medical school, the lower part of figure 2 ( $\%$ in hospital) shows the relative proportion of women in hospital medicine rose consistently through the 1940 to the 1965 cohorts, and then levelled out at 80-90\% (that is, proportionately, for every 10 men entering hospital medicine, 8 or 9 women will do so).

SAMPLE SIZES

It is not practical for space reasons to provided detailed information on sample sizes in all cases. However, to give the reader a sense of the numbers involved, in 1978 and 1996 there were 12285 and 20300 consultants, 2718 and 5907 Senior Registrars, 5690 and 5467 Registrars, and 8722 and 14756 senior house officers. In 1996 the numbers of consultants in the various speciality groups were 5743 in Hospital Medicine (Internal Medicine), 4515 in Surgery, 1799 in Radiology and Radiotherapy, 1887 in Pathology, 2432 in Psychiatry, 2780 in Anaesthetics, and 1039 in Obstetrics and Gynaecology.

INDIVIDUAL SPECIALTIES

The picture in individual hospital specialties may differ from the picture overall; in addition, their study also allows analysis of career preferences and hence intentions at application and qualification. Pathology, psychiatry and radiology/radiotherapy (fig $3 \mathrm{~A}-\mathrm{C}$ ) show similar patterns, the lines for SHOs, registrars, SRs and consultants being superimposed, implying no disproportionate promotion from SHO through to consultant grade. The other specialties are different (fig 3D-G). Surgery, hospital medicine and $\mathrm{O}$ and $\mathrm{G}$ show disproportionate 
promotion from SHO to higher grades, with little evidence of disproportionate promotion beyond the registrar grade. Anaesthetics shows disproportionate promotion between all career grades, including SR to consultant (there being a lower percentage of female registrars than SHOs, senior registrars than registrars and consultants than senior registrars). The data for $O$ and $G$ (and perhaps surgery) also show "dog-legs" in the lines for consultants and SRs, implying a structural change, perhaps reflecting an alteration of policy.

\section{SECULAR TRENDS}

Psychiatry and pathology are more popular for later cohorts of women doctors, the proportion rising more steeply and exceeding the proportion entering medical school. Hospital medicine and $\mathrm{O}$ and $\mathrm{G}$ are similar but starting at a lower base. In contrast, the increasing proportions of women in surgery, radiology/ radiotherapy and anaesthetics only parallel the rising proportions entering medical school.

CAREER INTENTIONS

The analysis so far has considered doctors in career posts. However, doctors intending to enter hospital specialties may be deterred before entering SHO grades. Conversely some SHOs or even registrars may have no long term
KEY POINTS

- The proportion of women doctors in hospital specialties in the UK from 1974 to 1996 has been examined using official statistics.

- A cohort approach was used to relate the proportion of women doctors at each career stage to the proportion of women in the same cohort of medical school applicants.

- The currently low proportion of women consultants is mostly explained by the historically low numbers of women entering medical school a quarter of a century earlier.

- The proportion of women in training grades has grown rapidly over the past 20 years in all specialties, and will soon be reflected in consultant numbers.

- Overall there is little evidence for a "glass ceiling", or disproportionate promotion, for women doctors. There are possible exceptions in some specialties, for which direct or indirect discrimination is a likely explanation.

intention of specialisation. By studying career intentions it may be possible to distinguish
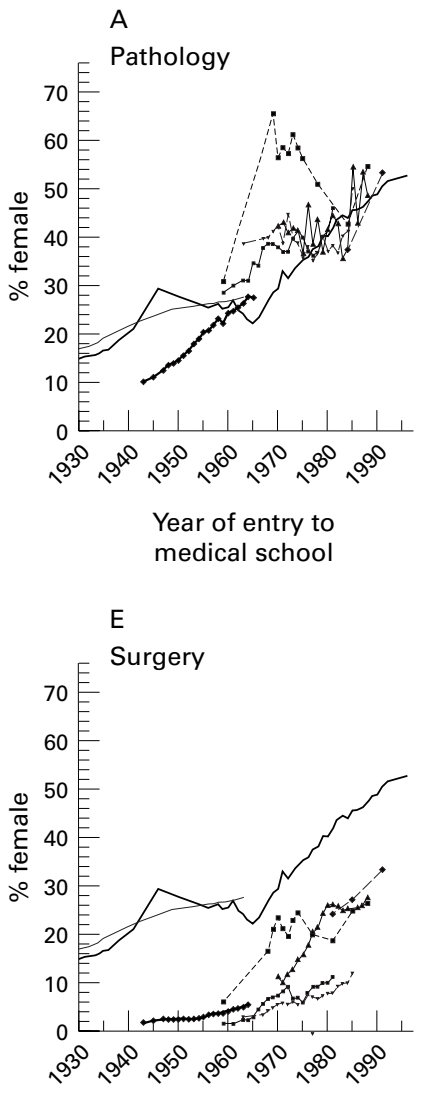

Year of entry to medical school

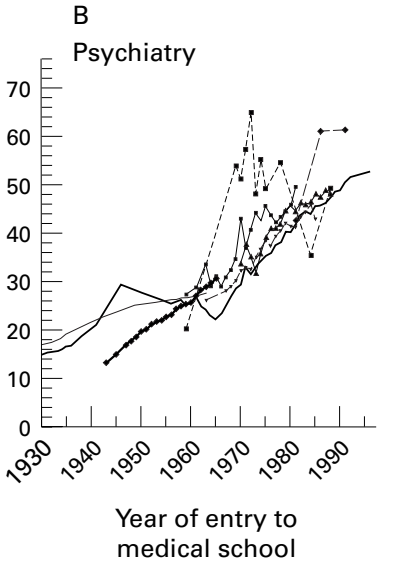

$\mathrm{F}$

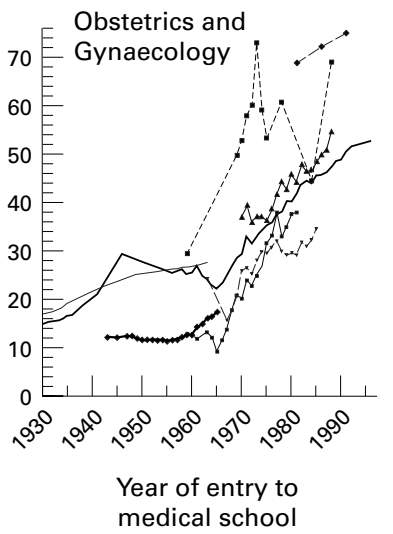

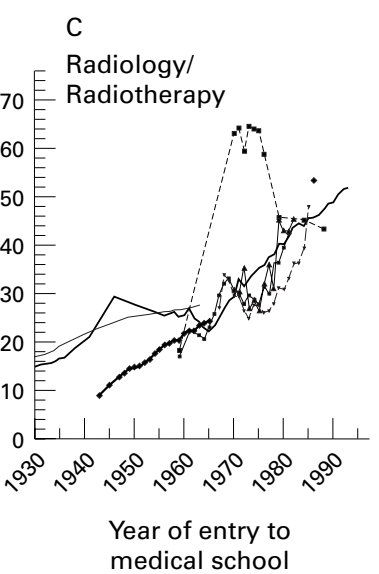

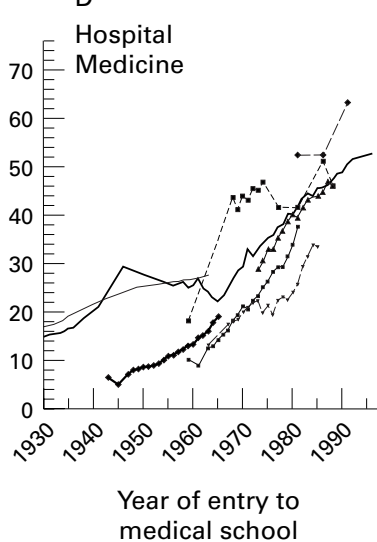

G

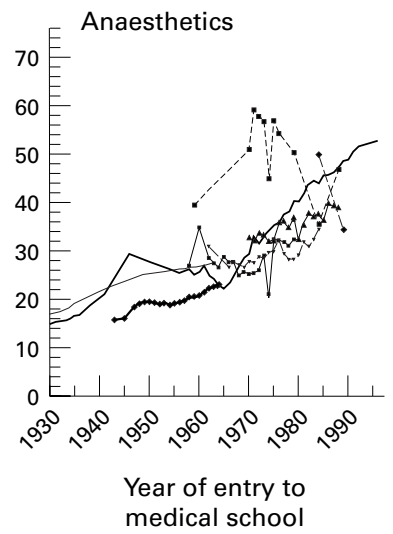

Figure 3 For each of the seven specialties is shown, in the same way as in figure 2, the proportion of women in each medical school entry cohort at the various career stages. The figures also show data on stated career preferences at the time of medical school selection, and in the final year or in the PRHO year, which are not distinguished. In specialties such as anaesthetics that are chosen by few applicants, cohorts have been averaged and plotted at the mid-cohort. Specialties are in general as defined in the statistics as published for 1993 in Health Trends, ${ }^{36}$ with the exception that Accident and Emergency is included as a part of surgery, Clinical Oncology is included as a part of Medicine, and $O$ and $G$ is considered separately from Surgery. Other and Dental specialties are ignored for present purposes. 
these cases, and to decide whether disproportionate promotion results from discrimination (direct or indirect) or active choice (which may include for instance family circumstances, dependants, partner and children). Career preferences have been plotted in figure $3 \mathrm{~A}-\mathrm{G}$ for medical school applicants, and for preregistration house officers or final year medical students (PRHO-FY).

Fewer women than men intend careers in surgery, although the proportion seems to be rising (fig 3E). PRHO-FYs show a similar pattern with women constituting only $20-30 \%$ of those intending a career in surgery. In more recent cohorts the proportion of female surgical SHOs is compatible with the career preference data. However, the discrepancy between career preference and the proportions of registrars/SRs suggests women have been actively deterred from surgical careers. A similar although less extreme situation applies in hospital medicine, with SHOs now reflecting career intentions, but there being a discrepancy with subsequent grades. Radiology/Radiotherapy, Pathology and Psychiatry all show a pattern of a rise and then a fall in career preference at the PRHO-FY stage (fig $3 \mathrm{~A}-\mathrm{C}$ ). $\mathrm{O}$ and $\mathrm{G}$ is an extremely popular career choice for women applicants and at PRHO-FY (fig 3F). The large discrepancy from the SHO level implies active dissuasion of women from the speciality. Anaesthetics (fig 3G) shows a similar discrepancy and again suggests active dissuasion from the speciality.

\section{Discussion}

Official statistics and survey data have been used to assess the careers of women in NHS hospitals. The lower proportion of women overall in senior hospital grades to a large extent reflects older doctors coming from cohorts with fewer women medical students; the rapid increase in women medical students in the past three decades is now being reflected as increasing proportions of women at all career levels in most specialties. The curious exception of anaesthetics with its almost constant proportions of women consultants, SRs, Registrars and SHOs is difficult to explain, and requires further exploration.

Disproportionate promotion is absent in psychiatry, pathology, radiology/radiotherapy, the proportion of women being similar at all rungs of the promotion ladder within cohorts. This is strong evidence for the absence of direct and indirect discrimination and differential choice.

Disproportionate promotion from the $\mathrm{SHO}$ grade occurs in surgery, $\mathrm{O}$ and $\mathrm{G}$ and hospital medicine, after which career progression seems to occur proportionately. The possibility that fewer women SHOs have serious intentions of staying in the specialty, using the posts only as part of a broader training, seems unlikely; hospital specialties overall (fig 2) show smooth transitions from the $\mathrm{SHO}$ grade, implying that women progress equally well in hospital careers overall, so that the specific lack of progress in medicine, surgery and $\mathrm{O}$ and $\mathrm{G}$, probably reflects women transferring to other specialties.
The data on career preferences in medical school applicants, final year students, and PRHOs suggest there is no lack of career intention in women for surgery, $O$ and $G$ and hospital medicine, so disproportionate promotion is not readily explained as differential choice. The implication is that women are being dissuaded or prevented from entering some hospital specialties.

It has been suggested that women need to achieve a critical mass of about $15 \%$ in a career before progressing satisfactorily to the highest level. ${ }^{52}$ We find little evidence for this overall (see fig 2), or in the individual specialties (fig 3); changes with time are mostly smooth, with no evidence of sudden increases at $15 \%$ or any other critical value.

There is clear evidence of secular trends in the popularity of particular specialties for women. In particular psychiatry became more popular for women, and hospital medicine and $\mathrm{O}$ and $\mathrm{G}$ now seem to be behaving similarly; in contrast pathology was disproportionately popular for earlier cohorts. Surgery has always attracted few women, and although numbers have increased in recent years, they are far from equivalent to numbers entering medical school, and there is perhaps a hint of "topping out". Overall the secular changes probably reflect women choosing between different hospital specialties, rather than between hospital and non-hospital careers, so that career choice must be seen as a dynamic, active process, with women (like men) choosing careers they find attractive and in which success is perceived as possible, with such factors varying between cohorts. The data preclude a static model of career choice, with fixed (or maximum) proportions of women doctors in particular specialties. Instead women (and men) match perceived opportunities and disadvantages in a specialty to their own interests and inclinations, thereby circumscribing their options. ${ }^{53}$

Our analysis suggests there is no "glass ceiling" for women doctors, and that generally, with a few prominent exceptions, there is no overall disproportionate promotion. However, disproportionate promotion does occur at some stages in hospital medicine, surgery, $\mathrm{O}$ and $G$ and anaesthetics, and as it is not easily explained as a result of differential choice, then it probably results from direct or indirect discrimination. The currently lower proportions of women in more senior grades primarily reflects historically lower proportions of women entering medical schools in the 1930s, 1940 s, 1950s and 1960s. As older cohorts of doctors are replaced by younger cohorts so the overall proportion of women rises at all levels of hospital practice.

The data from this study are principally quantitative, and derived from official statistics, and therefore it is not straightforward to derive specific explanations of the motivations and drives of the women doctors in the study for their career choices. In particular it is not easy to assess whether they would see themselves as actively making choices, or as passively influenced by circumstances, in the form of career opportunities and lifestyle and 
living constraints. These are important questions, and would be better considered in part by more qualitative research programmes, rather than the present numerical approach. Such a qualitative approach could be complementary to a more extensive methodology derived from the present type of analysis. The strength of this paper is in the comprehensive nature of the statistics, and the large sample sizes. The weakness is in the fact that it is retrospective, so that its predictive value is limited. In future it may be possible to carry out large scale prospective studies, perhaps based on the type of data collected by the Medical Workforce Research Group, ${ }^{47} 5455$ where entire cohorts of doctors, both male and female, are asked not only about career intentions (as at present), but also about motivations, constraints and opportunities. That should allow the teasing apart of the issues raised in this study. A further possibility for further research is to examine comparative data, from the health care systems of other countries. In a recent example, data from Norway $^{56}$ have shown that despite forceful equal opportunities policies, positive sex discrimination, improved social benefits, workplace creche facilities, and daycare funding, women doctors are still less likely to reach senior positions in medicine; the exceptions are in specialties such as paediatrics in which there is a high proportion of women doctors. The explanation for such findings is not at all clear, although, in a related commentary, ${ }^{57}$ Showalter points to limitations imposed by "the hierarchical system of medicine", and "the very structure of medical training (which) creates a mystique of stamina, fierce dedication, and stoic endurance, so that deviation from the norm, however licensed, spells weakness rather than leadership potential". Certainly that description is compatible with Cassell's account of the career barriers experienced by American woman surgeons. ${ }^{13}$ A further route for future research is to put the data reported here on medicine into a much broader context of education and training in general, where there is a growing number of studies of the choices made by men and women at different stages of school and university education, and subsequent careers. ${ }^{58}$ As a single example, it has been pointed out that although in the UK the introduction of a national Curriculum has meant that most students at school will study science to the age of 14 or 15 , that has not changed the subsequent male excess of students taking science subjects after that age, when students make a free choice of subjects. ${ }^{59}$ To some extent therefore it has to be accepted that career choices are precisely that, choices, and these are not entirely the result of social forces outside the person, but also reflect their own wishes, needs and desires. Separating those two components has to be a research need for both public health and social policy. People who are working in careers where they wish to be working are more likely to be satisfied, productive, effective professionals, than those who feel that they have been marginalised or coerced into a specialty that is not of their own choosing. As such the career choices of doctors have broader implications for the public health in general.

We are grateful to Mrs Gill Bellord and Mr Nigel Palmer for their assistance with historical data. KAS was supported by a their assistance with historical data. KAS was supported by a cohort study was funded by the Leverhulme Trust and the cohort study was funded by the Leverhulme Trust and the
Department of Health, and the 1986 medical student cohort Department of Health, and the 1986 medical student cohort study was funded by the Economic and Social Research Coun-
cil. Mr Mark Stephenson of the NHS Executive was extremely cil. Mr Mark Stephenson of the NHS Executive was extremely
helpful in providing unpublished workforce data for 1993 to helpful

Conflicts of interest: none.

1 Lefford F. Women doctors: a quarter-century track record. Lancet 1987;i:1254-6.

2 Coulson J. Women want opportunity in macho medical world. BMA News Review 1994;21-2.

3 Elston MA. Women doctors in a changing profession: the case of Britain. In: Riska E, Wegar K, eds. Gender, work and medicine: women and the medical division of labour. London: Sage, 1993:27-61

4 Firth-Cozens J. The five years after qualification. BMf 1994;309:1524-5.

5 Parkhouse J. Doctors' careers. London: Routledge, 1991.

6 Bickel J. Women in medical education. N Engl f Med 1988; 319:1579-84.

7 Allen I. Doctors and their careers. London: Policy Studies Institute, 1988.

8 Allen I. Doctors and their careers: A new generation. London: Policy Studies Institute, 1994

9 Anonymous. Women doctors and their careers: Report of the Anonymous. Women doctors and their careers: Report of the
joint working party. London: Department of Health, 1991. joint working party. London: Department of Health, 1991 .
Anonymous. Medical staffing and prospects in the NHS in England and Wales, 1977. Health Trends 1978;10:61-4.

11 Anonymous. Monopoly of middle-aged men. [Editorial]. Lancet 1991;337:1007-8.

12 Lorber J. Why women physicians will never be true equals in the American medical profession. In: Riska E, Wegar K, eds. Gender, work and medicine: women and the medical division of labour. London: Sage, 1993:62-76.

13 Cassell J. The woman in the surgeon's body. Cambridge, MA: Harvard University Press, 1998.

14 Currie C. Role models and patronage. BMF 1993;306:7356.

15 Lorber J. Women physicians: careers, status and power. New York: Tavistock, 1984

16 Wolf TM, Randall HM, von Almen K, et al. Perceived mistreatment and atitude change by graduating medical students: a retrospective study. Med Educ 1991;25:182-90.

17 Baldwin DCJ, Daugherty SR, Eckenfels EJ. Student perceptions of mistreatment and harassment during medical school. A survey of ten United States schools. West $\mathcal{F} \mathrm{Med}$ 1991;155:140-5.

18 Lenhart SA, Klein F, Falcao P, et al. Gender bias against and sexual harassment of AMWA members in Massachusetts. $\mathcal{F}$ Am Med Wom Assoc 1991;46:121-5.

19 Nickerson KG, Bennett NM, Estes D, et al. The status of women at one academic medical center. Breaking through the glass ceiling. $尹 A M A$ 1990;264:1813-17.

20 Tesch BJ, Wood HM, Helwig AL, et al. Promotion of women physicians in academic medicine. Glass ceiling or sticky floor? fAMA 1995;273:1022-5.

$21 \mathrm{McGoldrick}$ KE. Shattering medicine's glass ceiling. $f \mathrm{Am}$ Med Wom Assoc 1994;49:3

22 Anonymous. Medical staffing and prospects in the NHS in England and Wales, 1978. Health Trends 1979;11:53-6.

23 Anonymous. Medical staffing and prospects in the NHS in England and Wales, 1979. Health Trends 1980;12:51-4.

24 Anonymous. Medical staffing and prospects in the NHS in England and Wales 1980. Health Trends 1981;13:57-60.

25 Anonymous. Medical and dental staffing and prospects in the NHS in England and Wales, 1981. Health Trends 1982; 14:28-33.

26 Anonymous. Medical and dental staffing prospects in the NHS in England and Wales, 1982. Health Trends 1983;15: 35-9.

27 Anonymous. Medical and dental staffing prospects in the NHS in Engalnd and Wales, 1983. Health Trends 1984;16: NHS

28 Anonymous. Medical and dental staffing prospects in the NHS in England and Wales, 1984. Health Trends 1985;17: 45-52.

29 Anonymous. Medical and dental staffing prospects in the NHS in England and Wales. Health Trends 1986;18:49-56.

0 Anonymous. Medical and dental staffing prospects in the NHS in England and Wales in 1986. Health Trends 1987;19:1-8.

31 Anonymous. Medical and dental staffing prospects in the NHS in England and Wales in 1987. Health Trends 1988;20:101-9.

32 Anonymous. Medical and dental staffing prospects in the NHS in England and Wales in 1988. Health Trends 1989;21:99-106.

33 Anonymous. Medical and dental staffing prospects in the NHS in England and Wales 1989. Health Trends 1990;22: 96-103. 
34 Anonymous. Medical and dental staffing prospects in the NHS in England and Wales 1990. Health Trends 1991;23 NHS in

35 Allen P. Medical and dental staffing prospects in the NHS in England and Wales 1991. Health Trends 1993;25:4-12.

36 Allen P. Medical and dental staffing prospects in the NHS in England and Wales 1992. Health Trends 1993;25:118-26.

37 Wilson R, Allen P. Medical and dental staffing prospects in the NHS in England and Wales 1993. Health Trends 1994; 26:70-9.

38 Elston MA. Women in the medical profession: Whose problem? In: Stacey M, Reid M, Heath C, et al, eds. Health and the divison of labour. London: Croom Helm, 1977:115-38.

39 Beaumont B. Changing working patterns of women doctors in the 1970s. In: Medical Women's Federation, ed. Careers symposium: Women in Medicine 1979 - What is our future? London: Medical Women's Federation, 1979:12-24.

40 Bewley BR, Bewley TH. Hospital doctors'career choices and the misuse of medical womanpower. Lancet 1975;ii: 270-2.

41 Ministry of Health. Report of inter-departmental committee on medical schools (The Goodenough Report). London: HMSO, medical sc.

42 University Grants Committee. University Development: From 1936 to 1947. London: HMSO, 1948.

43 University Grants Committee. University Development: Report on the years 1947 to 1952 (Cmd 8875). London: HMSO, 1953.

44 Ministry of Health. Report of the Committee to consider the future numbers of medical practitioners and the appropriate intake of medical students (The Willink Report) London: HMSO, 1957.

45 Royal Commission. Royal Commission on Medical Education (The Todd Report), Cmnd 3569. London: HMSO, 1968.

46 Last JM, Stanley GR. Career preference of young British doctors. British fournal of Medical Education 1968;2:13755.
47 Lambert TW, Goldacre MJ, Edwards C, et al. Career preferences of doctors who qualified in the United Kingdom in 1993 compared with those of doctors qualifying in 1974 , 1977, 1980, and 1983. BMf 1996;313:19-24.

48 McManus IC, Richards P. An audit of admission to medical school: 1. Acceptances and rejects. BMF 1984;289:1201-4. 49 McManus IC, Richards P, Maitlis SL. Prospective study of the disadvantage of people from ethnic minority groups applying to medical schools in the United Kingdom. BMf 1989;298:723-6.

50 McManus IC, Richards P, Winder BC, et al. Medical school applicants from ethnic minorities: identifying if and when they are disadvantaged. $B M \mathcal{F} 1995 ; 310: 496-500$

51 McManus IC, Richards P, Winder BC, et al. The changing clinical experience of British medical students. Lancet 1993;341:941-4.

52 Etkowitz H, Kemelgor C, Neuschatz M, et al. The paradox of critical mass for women in science. Science 1994;266:514.

53 Gottfredson LS. Circumscription and compromise: A developmental theory of occupational aspirations. Fournal of Counseling Psychology Monograph 1981;28:545-79.

54 Lambert TW, Goldacre MJ, Parkhouse J. Intentions of newly qualified doctors to practise in the United Kingdom. BMF 1997;314:1591-2.

55 Edwards C, Lambert TW, Goldacre MJ, et al. Early medical career choices and eventual careers. Med Educ 1997;31: 237-42.

56 Kvaerner KJ, Aasland OG, Botten GS. Female medical leadership: cross sectional study. BMF 1999;318:91-4.

57 Showalter E. Improving the position of women in medicine. BMF 1999;318:71-2.

58 Radford J. Gender and choice in education and occupation. London: Routledge, 1998.

59 Colley A. Gender and subject choice in secondary education. In: Radford J, ed. Gender and choice in education and occupation. London: Routledge, 1998:18-36. 